\title{
Personality, Political Attitudes and Participation in Protests: The Direct and Mediated Effects of Psychological Factors on Political Activism*
}

\author{
Ednaldo Aparecido Ribeiro \\ Universidade Estadual de Maringá, Brazil \\ Jullian Borba \\ Universidade Federal de Santa Catarina, Brazil
}

\begin{abstract}
Studies combining psychology and political science have shown that personality traits such as extroversion and openness to experiences are conditioning factors of political activism. However, the mechanisms through which this effect occurs are still poorly understood. Aiming to advance this topic, this article presents the results of an investigation that looked to analyse the mediated effects of personality traits in the Brazilian context, taking as mediating conditioning factors various attitudes and subjective dispositions commonly found in the literature, such as interest in politics and subjective political efficacy. Using the Latin American Public Opinion Project data, the hypothesis was tested that personality influences behaviour, since it favours the development of a number of attitudes that function as basic factors conditioning civic engagement. The results indicate the significant mediated effects of extroversion and openness to experience, especially with regard to political knowledge.
\end{abstract}

Keywords: Personality; political participation; protest; civic skills; mediated effects. 
lthough the first generation of studies on political participation focused
-its attention on electoral modalities such as voting and party engagement, new forms of activism became absorbed into research agendas after the 1960s, particularly those studies linked to protests (NORRIS, 2007). Part of the literature concerned with these new forms of political citizenship has sought to identify their conditioning factors at a macrosocial level (DALTON and ROHRSCHNEIDER, 2002; TARROW, 1998), associated with the political and economic structure of countries and global regions, but also the factors at a micro level (VERBA, SCHLOZMAN and BRADY, 1995), such as material resources (income) and cognitive resources (schooling, knowledge of politics). Focusing attention on this dimension of individual conditions, the present article discusses a component still seldom explored by political scientists: personality.

Some researchers investigating the psychology of individual differences have argued that personal traits should be considered when explaining participatory political behaviour (MONDAK, 2010). However, this provocation has generated few responses from Political Science and there have thus far been few attempts to empirically test the relations between personality traits and different forms of political engagement. Some pioneering initiatives in the area should be highlighted, such as the work of Mussen and Wyszynski (1952), who back in the 1950s had observed that less participatory individuals had a tendency towards passivity, inflexible thinking and submissiveness towards authority, and Sniderman (1975), who published Personality and Democratic Politics, showing that participation was associated with high self-esteem.

This relative disinterest can be partially explained by the difficulty involved in defining what personality is and by the absence of a basic taxonomy that could be used in empirical studies for the purpose of generating reliable data (MONDAK et al., 2010). Nonetheless, this scenario has altered significantly over the last decade and such obstacles have begun to erode with the development of instruments capable of capturing these psychological structures in a sufficiently succinct form to be included in conventional questionnaires. The immediate effect of these advances has been the recent publications of a number of studies venturing into the terrain of relations between participatory political behaviour and personality (DENNY and DOYLE, 2008; MONDAK, 2010; MONDAK and HALPERIN, 2008; MONDAK et al., 2010; 


\section{VECCHIONE and CAPRARA, 2009).}

Most of these works, however, focus attention on voting behaviour and other forms of activism linked to representative institutions (BLAIS and LABBE St-VINCENT, 2011; DENNY and DOYLE, 2008; GERBER et al., 2010). The works of Mondak (2010), Mondak et al. (2011) and Galego and Oberski (2012) are exceptions in this context since they have specifically examined forms of protest and will consequently be discussed later in this article. It is important to stress that these few studies take as their empirical baseline nations like the United States, the United Kingdom and, in the case of the last-mentioned study, Spain. Research conducted in countries that have experienced democratization processes relatively recently, such as those of Latin America, is even rarer, therefore. The sole exceptions regionally are two works by Mondak and collaborators published in 2010, but which are limited to just two countries (Uruguay and Venezuela).

For our own regional context, we aimed to contribute to this field by providing an initial exploration of these relations in Ribeiro and Borba (2016), in which we found interesting evidence concerning the effect of some personality traits on involvement in political protests. In this work, we point to the need to deepen our understanding of these effects through interactive strategies between the individual personality and other factors conditioning attitudes already regularly identified in studies on participation.

Seeking to advance in this direction, the present article presents the findings of an investigation that looked to ascertain the extent to which these individual psychological traits favour the manifestations of political attitudes or subjective attributes identified by the literature as relevant factors in explaining engagement (NORRIS, 2007; VERBA, SCHLOZMAN and BRADY, 1995), concentrating here exclusively on the Brazilian context. In this sense, our intention is to analyse this impact in mediated form, taking such subjective attitudes and dispositions as intermediary conditioning factors. The article thus constitutes an attempt to assess the paths or mechanisms through which psychological characteristics affect participatory dispositions in this national context.

Before proceeding to the study's findings, the relative novelty of this kind of investigation, an approach connecting individual psychological dimensions to patterns 
of civic behaviour, makes it appropriate to clarify the various categories, basic concepts and measuring procedures used, as well as to provide a brief review of recent advances in this research agenda in the field of Political Science. Consequently, the present introduction is immediately succeeded by a section discussing the significance of personality as an empirically observable object. This is followed by a review of the main publications to have recently examined this interrelation between personality and political behaviour, focusing more specifically on studies that address protest activism. Finally, the third section presents and discusses the results of the research.

\section{Personality: concept, contents and measurement}

The significance of personality as a concept and an object of research has been a polemical issue among psychologists for a long time, to such an extent indeed that one leading researcher wrote back in the 1970s that "personality is like love: everyone agrees it exists, but disagrees on what it is" (CATTELL, 1973, p. 41). Decades have passed since and the divergence continues to exist, although important steps towards a minimum level of consensus have been taken, especially over the last twenty years.

Since our intention is to investigate the relationship between personality and protest-based political participation, though, we are compelled to adopt a position in this debate by providing a definition viable in terms of the empirical testing of hypotheses drawn from the field of research on political behaviour, based on the kinds of data normally used in the area. As in the case of other research objects, personality can be defined in various forms for a wide variety of purposes, but few of these definitions are applicable in methodological and technical terms by political scientists in their day-to-day research activities.

In the search for an operationalizable definition, one of the primary conceptual approaches associates personality with a multifaceted and enduring internal (or psychological) structure (MONDAK, 2010). This perspective implicitly contains the understanding that such a structure is strongly influenced by biological factors, constituting, therefore, something intrinsic in each of us from birth, defining much of who we are and shaping our behaviours. There already exists a considerable volume of research identifying the genetic bases of individual differences in personality, such as McCrae et al. (2001), who identified that this order of factors explains more than $50 \%$ of 
the variation in this internal structure. Yamagata et al. (2006), through studies with twins in North America, Europe and Asia, discovered that this influence remains constant among the different geographic regions, lending further support to the hypothesis that a universal genetic personality structure exists independent of learning or acculturation processes.

The multifaceted nature of the psychological structure leads us to the concept of personality factors ${ }^{1}$, which can be understood as the basic categories of individual differentiation at work, which, due to their observable nature, are normally expressed by observers through adjectives (WINTER, 2003). When we refer to someone as introverted, timid or sociable, we are making use of adjectives to refer to relatively stable patterns of behaviour that this person tends to display in specific situations: in other words, as observers we identify and name the factors (components or traits) that constitute the subject's personality.

For a long time, however, the studies dedicated to identifying these factors ran the serious risk of creating a semantic nightmare by attempting to catalogue all the adjectives employed to represent behavioural patterns or characteristics that configure the individual differences that distinguish us from each other. For many decades a multitude of different scales prevailed that contributed more to impede than advance a consistent research agenda. This situation would only change in the 1990s when a new generation of holistic models started to emerge for studying traits, notably 'Five-Factor Theory' (GOLDBERG, 1992)22 and 'Big Five Theory' (COSTA and McCRAE, 2003).

In this work we adopt this second theory. Hence, we shall discuss it in a bit more detail. For Costa and McCrae (2003), a highly comprehensive and hierarchized model for describing and comprehending the structure of personality can be composed by just five main factors: openness to experience, conscientiousness, extraversion,

\footnotetext{
${ }^{1}$ Personality involves other elements beyond these factors, such as beliefs and motivations, but due to the difficulty of incorporating the latter into empirical research on political behaviour, they will not be considered here.

2 Although similarly founded on the lexical hypothesis that the most salient individual differences are expressed through natural language, Goldberg's approach (1990) diverges from Costa and McCrae's proposal (2003) by not being hierarchical. Each pair of factors (extraversion, agreeableness, conscientiousness, emotional stability and intellect) form circles within a bidimensional space. Once the angular position is located, the item is projected to the perimeter of a circle and a variety of potential combinations of combined factors are generated from the five initial ones. According to this circular perspective, then, many interstitial items exist.
} 
agreeableness and emotional stability.

The development of this comprehensive and functional perspective can be seen as the outcome of many decades of efforts devoted to identifying the fundamental traits that compose this internal structure. Based on the pioneering work of Allport and Odbert (1936), who compiled roughly 18,000 terms utilized to refer to traits, researchers like Cattell (1947) began to apply techniques for reducing this size (such as factorial analysis) with the intention of producing a smaller set of basic components that could synthesize all this variety of adjectives. As a result of several years of tests, Cattell (1956) presented a fairly promising model containing sixteen factors known as 16PF (16 Personality Factors). Years later Tupes and Christal (1961), reassessing Cattell's scale (1956), arrived at a structure containing just five components.

Between the 1960s and 1970s, a period of strong scepticism prevailed in relation to all approaches based on identifying these traits and especially concerning the possibility of such reduced scales being able to capture the complexity of the human personality (MISCHEL, 1968). But in 1980 a new generation of researchers took up the project again and by the end of the decade Goldberg (1992), Costa and McCrae (2003) were already coordinating important research programs based on the structure of five major factors (MONDAK, 2010).

The two decades that succeeded the rebirth of this psychological line of inquiry were dedicated almost exclusively to validating its scales and procedures. In relation to validation, the advocates of this approach sought to respond primarily to criticism over the use of scores derived from self-evaluations by research subjects on their own characteristics. The risk that the instruments used in data surveys might reflect selfillusions and social desirability was fairly high and a lot of effort was made to seek controls for these interferences (MONDAK, 2010). McCrae and Costa (1989), for example, developed a test based on comparing the points attributed by the individuals to themselves for each of the components with the points attributed by an observer and they discovered significant correlations of 0.56. More recently, Connolly et al. (2007), reviewing the literature on this topic, identified correlations that range from 0.46 (in relation to agreeableness) to 0.62 (in relation to extraversion). These results indicate that self-evaluation and external evaluation do not result in identical points between the five traits, but they do reveal a strong congruence between them, which favours the 
acceptance of the methodology based on self-perception.

Considerable effort has been made in recent years to verify the validity of the data collection tools, as well as the five major factor structure itself, in linguistic and cultural contexts different from those in which the perspective was developed. The results produced thus far reveal a substantial applicability of the approach in diverse contexts (McCRAE and COSTA, 2006).

We turn now to a brief description of each of the components making up the model, beginning with Openness to Experience. McCrae and Costa (2003) define this factor as a multifaceted dimension that includes intelligence, perception, aesthetic sensibility and an intrinsic attraction towards new experiences ${ }^{3}$. This primary factor is the one that exerts the most tension on the limits of language, making it irreducible to a single word as is usual in lexical approaches like the Five-Factor and Big Five models. To refer to someone with low points in this dimension, McCrae and Costa (2003) employ phrases like "insensible in relation to arts and beauty" and "border by discussions of ideas" (McCRAE and COSTA, 2003, p. 123).

This trait has been more often investigated by researchers concerned with the world of work, associated mainly with creative behaviours in the exercise of work activities, but also with low loyalty to organisations (MOSS et al., 2007) and ease of adaptation to international productive activities (HUANG, CHI and LAWLER, 2005). Beyond the work environment, this characteristic has also been associated with risk behaviours, such as drink-driving and also tobacco use (BOOTH-KWLEY and VICKERS, 1994).

Conscientiousness involves adjectives linked to reliability such as 'organisation', 'punctuality' and 'reliable' and some authors tend to include too a volitional content with terms like 'hard-worker' and 'persevering' (MONDAK, 2010). Predictably enough, studies identified the association of this trait with high income and work productivity (DUDLEY et al., 2006). In a laboratory-based study, Horn, Nelson and Brannick (2004) encountered a strong connection between conscientiousness and honest behaviour in different simulated situations. In the health area, evidence exists

3 Goldberg (1992) uses the term 'intellect' to refer to a dimension equivalent to openness to experience. However, his emphasis is on characteristics like 'analytic', 'curious' and 'imaginative'. In this sense he overemphasizes attributes linked to the cognitive dimension. 
that individuals with high scores in this component tend to adopt more healthy lifestyles, especially in terms of regular physical activity, and present an above average life expectancy (FRIEDMAN et al., 1993).

The Extraversion factor is the one with the longest history in the psychology of individual differences. Eysenck (1947) includes this trait in his two-factor model and Cattell (1956) in his aforementioned 16-trait tool (16PF). The main adjectives used to represent this component are 'energetic', 'bold', 'talkative' and, of course, 'extravert' (MONDAK, 2010). In the work environment the trait has been associated with strong organisational commitment and a tendency towards compulsion for work (BURKE, MATTHIESEN and PALLESEN, 2006). Professional success in areas linked to sales and academic skills has also been associated with high scores in this factor (PULFORD and SOHAL, 2006).

Agreeableness, for its part, is the factor with least research tradition and the empirical evidence concerning its effects are also reduced. It basically involves a disposition favourable to the establishment of positive interpersonal relations and the instruments employed to measure it normally make use of terms like 'warm', 'friendly' and 'sympathetic' (MONDAK, 2010). At work, individuals with high scores in this factor tend to present more facility with group activities and better adaptability to new jobs (BARRICK and MOUNT, 1991), as well as higher career stability (LAURSEN, PULKKINEN and ADAMS, 2002). In the health area associations were found with low levels of alcoholism and depression (LAURSEN, PULKKINEN and ADAMS, 2002).

Finally, Emotional Stability has as long a tradition as Extraversion. In their research instruments, Tupes and Christal (1961) already included subfactors to measure this dimension among US armed forces recruits. The adjectives used today in the measuring instruments are 'calm', 'relaxed', 'stable' (MONDAK, 2010). Differently to what we have seen with the other factors, this last one does not present significant effects in phenomena linked to the work environment, but in compensation has shown serious medical implications, such as the propensity to high levels of stress, tension and depression when low scores are recorded (BOLGER and SCHILLING, 1991).

To conclude this brief presentation it is worth including some basic information on the methodological and technical procedures used in the studies on the theme. For Mondak (2010), there exist two types of investigation in this area that are distinguished 
mainly by the measurement strategies employed to construct their indicators. In the first group are the studies that concentrate on the properties of the factors themselves, looking to confirm their real existence, identify their subsidiary elements and demonstrate their validity in different cultural and linguistic contexts. In the second group we find studies that set out from the premise of the existence of this structure of five main factors in order to investigate its consequences and effects on attitudes and behaviours.

Reflecting their objectives, the researchers of the first group tend to make use of fairly broad scales, such as Costa and McCrae (2003), who use an instrument with 240 items, and Goldberg (1992), who adopts a set of 50 items. Because of this amplitude the studies are normally conducted with small samples, generally composed of voluntary students.

In the applied research of the second group, application of lengthy sets of items is not viable given the study objectives and limitations, especially because alongside measuring the components themselves, researchers also need to collect all the information relating to attitudes and behaviours that will be associated with the personality structure at the moment of analysis. Additionally, since these are research studies that aim to show associations or effects within a given population, they need to adopt rigorous sample procedures, which implies working with large samples. The time need to apply instruments to a considerable number of subjects makes it necessary to reduce the set of items on personality in order to reduce the time required to collect data.

In constructing these reduced sets of items, researchers normally use bipolar or semantic differentiation scales that contrast pairs of adjectives, thereby affiliating to the lexicological approach to studies of personality, which advocates capturing these factors through their expression in colloquial language (MONDAK, 2010). In practical terms these instruments present research participants with a varied set of scales whose poles are represented by contrasting adjectives, like 'talkative-quiet', 'extravert-introvert', 'organised-disorganised', and so on. The interviewees are invited to assess themselves and choose a point on a scale from 0 to 10 between these poles. The instrument of sixteen items developed by Cattell (1956) already used this approach of contrasting pairs and even today this is the format most often employed in applied research. 
Although more comprehensive scales enable the identification of nuances in subsidiary traits, Mondak (2010) provides an interesting review of publications that have tested the findings of minor scales and reached the conclusion that instruments based on just five or ten items are just as reliable in identifying the five major traits. As we explain later, our research used data produced through the application of a set of ten items, each trait composed by two scales with pairs of contrasting adjectives.

Having briefly set out the concept of personality that oriented our research and its main contents, in the next section we review the main studies that have recently sought to relate the main factors to specific political behaviours.

\section{Personality and political participation}

Though still rare, studies of the relation between the major personality factors and political behaviour, the concern with the possible relations between individual psychological characteristics and more general political phenomena has a long history. Focusing only on the main contributions of the twentieth century, we can particularly mention the studies based on psychobiographies of elites (ERIKSON, 1969; GEORGE and GEORGE, 1964; GREENSTEIN, 2003; RENSHON, 1995), the research on adherence to democratic values (ADORNO, 1950; EYSENCK, 1954; STENNER, 2005) and also the investigations into tolerance and dogmatism (ROKEACH, 1960; SULLIVAN, PIERESON and MARCUS, 1982).

The studies that concentrate on political behaviour have a much shorter history and the number of works is significantly smaller. Mondak (2010) identifies three main reasons for this lack of attention. The first concerns the difficulty of data collection since, until very recently, the sets of questions needed to capture the structure of psychological differences were very long, making their inclusion in surveys organised by political scientists inviable. The second reason is linked to the absence of any consensus on a concept of personality, even among psychologists. In other words, even if a political scientist were disposed to include a long set of questions to measure these individual internal characteristics, there would be no consolidated guidelines to determine which of the various definitions and contents would be the most suitable. Finally, the third reason involves the lack of a general theory of personality capable of explaining its 
biological and environmental origins, its mechanisms of interaction with situational dispositions and its effects on human behaviour in general.

The first two reasons have played less of a role over recent years thanks to the emergence and consolidation of perspectives based on the five major fundamental traits, including the Big Five (COSTA and McCRAE, 2003) and the Five Factor Theories (GOLDBERG, 1992). The last obstacle, however, still remains and will only be surmounted by continued research and the accumulation of evidence.

Following the emergence of a basic level of consensus concerning the concept and contents of the human personality, combined with the development of more economical instruments for identifying and measuring its components, over the last decade works have begun to be published that empirically explore the effect of personality traits on themes such as access to information, frequency of discussion on politics, interest in politics, contacts with authorities, electoral turnout, participation in campaigns, and engagement in protests and demonstrations.

Utilizing data from two different telephone surveys conducted in the United States, Mondak (2010), for instance, tested the effects of the five major factors on different measures of access to print media and television, concluding that only the dimension of Extraversion was significantly associated with more frequent searches for information. Mondak et al. (2010) present tests on the effects of the factors on the establishment of contacts between citizens and political authorities with the results indicating strong positive effects of Extraversion on all forms of contact and a similar impact of Openness to Experience on direct contacts. Concerning electoral turnout, Denny and Doyle (2008) utilized the Five Factor approach of Goldberg (1992) to analyse the factors determining voting in the 1997 British general elections, comparing the effects of the personality dimensions with those produced by one of the most important predictors of this kind of behaviour: schooling. The results indicated that the most relevant items are 'hard-working versus lazy' and 'calm versus aggressive', with the most hard-working and most aggressive presenting a greater propensity to vote. Gerber et al. (2008), also using a different approach to the Big Five model, carried out a field experiment and discovered a significant effect of personality traits on electoral turnout probability among US voters. Gerber et al. (2011), for their part, employing the Big Five approach to the analysis of survey data collected by telephone and internet, identified 
positive effects of Extraversion and Emotional Stability, in some cases equivalent to those produced by education. Mondak and Halperin (2008) also investigate the involvement in campaign activities, identifying effects of Extraversion on participation at meetings and rallies.

While there are few works looking to apply the current psychological approaches on personality to the study of the bases of political behaviour in general, there is even less research on the impact of these individual differences on the involvement on mobilizations linked to political protests.

Even the works that approach this specific theme do so in a more or less marginal form. This is the case of the article by Mondak et al. (2010), who, in the middle of analyses involving data on the United States, Uruguay and Venezuela, introduces the variable on involvement in protests into one model. Even more problematic is the work by Vecchione and Caprara (2009) where involvement in demonstrations is inserted as a component of an indicator on participation that also contains pamphlet distribution, donation of money to a political association, contacts with politicians, and work for a political party.

All the studies mentioned up to now seek to test the effects of personality on political behaviour through multivariate models that include demographic and socioeconomic controls such as age, sex, income and education. Few models also bother to include attitudinal predictors to identify the persistence of the effects of psychological traits, making it impossible to identify effects potentially mediated or moderated by subjective attitudes or dispositions.

Among the exceptions in this field, we can point to the work of Blais and LabbeSt-Vincent (2011) on the indirect effects of a set of second-order personality traits (altruism, shyness, efficiency and conflict aversion) on electoral turnout. The authors identified that the effects of these traits vanished when they were included in the variable models relating to political preferences and the perception of voting as a duty. Since these attitudinal measures exerted a significant effect on turnout and were influenced by personality variables, they concluded that a mediated relation exists between these psychological characteristics and the act of turning out at voting venues.

More recently, Galego and Oberski (2012) proposed a model of causality in the form of a 'funnel' through which more distant (or anterior) factors like sex, age and 
personality influenced political attitudes that are more proximate causes of behaviours. The different compositions of personality are seen to affect, for example, an individual's level of interest in topics related to politics, which may strongly influence the chances of objective civic engagement. To test the applicability of this model, the authors explore what they call the indirect effects of personality on political participation, limited to electoral turnout and involvement in protests, taking as mediators attitudinal and behavioural variables like interest in politics, internal effectiveness, frequency of discussions of politics, and the perception that voting is a duty. Presenting a major advance in relation to the works of Vecchione and Caprara (2009) and Mondak et al. (2010), in this research protest is divided into its most recurrent modalities: demonstrations, strikes, boycotts (for political or environmental reasons) and illegal protest activity.

The findings reported by Galego and Oberski (2012) suggest that we need to consider the moderating or mediating functions of attitudes in the models that aim to associate personality with political behaviour. Inspired mainly by this latter work, in the next section we present our main hypotheses concerning these indirect effects in the national setting, as well as providing details on the procedures adopted to carry out the tests.

\section{Hypotheses, data and methodology}

In a previous work, Ribeiro and Borba (2016), we tested the direct effects of the five major factors of personality on the involvement in political protest for a broad set of Latin American countries, identifying significant impacts for Openness to Experience, Extraversion and Agreeableness. Setting out from these findings, our intention is to analyse these effects mediated by attitudinal factors.

The first test that we propose concerns the trait Openness to Experience, one of those most associated by the literature with dispositions interested in and cognitively mobilized by politics (HAMBRICK et al., 2008; WOLAK and MARCUS, 2007). Although, in Ribeiro and Borba (2016), we identified significant effects of this trait in a few Latin American countries, in Brazil this impact was pronounced even when controlled by important sociodemographic variables like age, sex and schooling. In this way we look to ascertain whether this effect continues to occur when mediating variables relating to 
political attitudes identified as relevant by the literature are included in the equation, as well as estimate the size of this effect, which may be understood as direct or indirect.

The second test involves Extraversion, whose direct effects were encountered for a larger number of national units (RIBEIRO and BORBA, 2016), but need to be confirmed through the inclusion of attitudinal controls mentioned in the previous paragraph. Just as Blais and Labbe-St-Vincent (2011) found in relation to electoral turnout, it is necessary to determine whether the effect identified previously continues after the inclusion of attitudinal controls, thereby excluding spurious conclusions.

Unfortunately it will not be possible to conduct tests involving Conscientiousness, a trait regularly linked to conflict aversion (MONDAK, 2010), since the database used lacks any mediating variable related to respect for social norms, as suggested in the work of Galego and Oberski (2012).

To perform these tests we use data produced by the 2010 edition of the Latin American Public Opinion Project (LAPOP) for the Brazilian context 4 . Up to now, this has been the only nationwide survey to apply an operationalizable scale for identifying personality traits in parallel with collecting information on political behaviour and attitudes, making it the only source available for the kind of research we propose. The project interviewed 2,482 people between March and April 2010 and was coordinated nationally by the University of Brasilia.

The five major traits or factors in the personality structure, according to the lexicological approaches put forward by Costa and McCrae (2003) and Goldberg (1992), are captured by the LAPOP study through a set of ten items that present contrasting adjectives, such that each of the factors is composed of two items. This set of questions is presented to interviewees with the following statement:

I'm going to mention a series of personality traits that may or may not apply to you. Using a scale of 1-7, where 1 signifies 'Strongly Disagree' and 7 signifies 'Strongly Agree', please tell me what number best indicates how much you agree or disagree with each statement. You should assess the extent to which each pair of traits applies to you, even of one trait applies better than the other (LAPOP, 2010).

\footnotetext{
${ }^{4}$ For technical information on samples, questionnaires and collection procedures, consult the technical documentation available at http://www.vanderbilt.edu/lapop/.
} 
The pairs of traits and their respective factors are presented below:

Table 01. Personality factors and items

\begin{tabular}{ll}
\hline Factors & Items \\
\hline Openness to Experience & $\begin{array}{l}\text { Person open to new experiences and intellectual } \\
\text { Person without creativity and imagination }\end{array}$ \\
Conscientiousness & $\begin{array}{l}\text { Person who can be depended on and is disciplined } \\
\text { Disorganised and careless person } \\
\text { Sociable and active person } \\
\text { Extraversion }\end{array}$ \\
Quiet and shy person \\
Agreeableness & $\begin{array}{l}\text { Critical and quarrelsome person } \\
\text { Calm and even-tempered person }\end{array}$ \\
Emotional Stability & Anxious and irritable person
\end{tabular}

Source: LAPOP Brazil Questionnaire 2010.

As the two items for each factor have inverse orders due to their contrasting nature, we firstly recodified the scales of the 'negative' adjectives, inverting their score in order to later enable the construction of a single integrated measurement for each of the five major traits. The result of this procedure was the reduction of the ten items to five factors with scales ranging from 0 to 12 . The distribution of these variables between the countries is within the patterns of normality necessary for their inclusion in regression models (between -01 and 01) (BORHSTEAD and KNOKE, 1989) $)^{5}$.

The involvement in protests, for its part, is measured by a dichotomous variable $(0=$ no and $01=y e s)$, generated by the following question: "In the last twelve months have you participated in any kind of demonstration or public protest?" (LAPOP, 2010). In the year analysed, the percentage of LAPOP interviewees who reported participating in these kinds of events was 5.9.

As we pointed out above, in a previous work, Ribeiro and Borba (2016), we identified considerable direct effects of Extraversion and Agreeableness on involvement in some Latin American countries included in the study. It is important to emphasize that these impacts proved consistent even with the inclusion of important sociodemographic controls (sex, age and schooling). These results, especially those related to Extraversion, led us to inquire into the mechanisms

5 Descriptive information (mean and standard deviation) can be seen in the Methodological Appendix I, available on line at BPSR website. See: bpsr.org.br/files/archives/Dataset_Ribeiro_Borba 
through which this influence operates and inspired us to formulate and test hypotheses that propose the mediation of this impact by variables related to what we can identify as civic cognitive attitudes and skills. The interest in politics, subjective political influence and knowledge of subjects related to national political life are emphasized as variables that might supposedly establish a connection between our independent variables (personality traits) and the dependent behavioural variable (involvement in protests). Since Extraversion is associated with a disposition towards social interaction (GALEGO and OBERSKY, 2012; MONDAK, 2010) and the exercise of an active political life involves interpersonal contact, it is, we think, plausible to suppose that this trait of individual psychology may be related to the display of greater interest in public affairs and that, in turn, this greater interest increases the chance of involvement in protest actions. This same effect of the trait of involvement, however, may also be related to the individual's self-evaluation of his or her capacity to influence political life: hence, the feeling of subjective political influence may affect how this impact occurs. Similarly, this greater propensity to social interaction among extraverts may be related to exposure to and assimilation of information related to the national public sphere, which may increase the probability of protest.

The variable Interest is operationalized by the answers to the question "How interested are you in politics: a lot, somewhat, a little, or not at all?" (LAPOP, 2010). In order to facilitate the interpretation of the results, we inverted the scale so that higher scores represented higher levels of interest. We thereby obtained a four-point scale (from 0 to 03 ) whose distribution among the national sample, though inclined (0.723), meets what the literature establishes as a level of proximate normality (BORHSTEAD and KNOKE, 1989).

Subjective Political Influence was constructed on the basis of two original variables derived from the following questions: 01. "You feel that you have a good understanding of the country's most important political issues. To what extent do you agree or disagree with this phrase?"; 02. "Those who govern the country are interested in what people like yourself think. To what extent do you agree or disagree with this phrase?" (LAPOP, 2010). The replies to both questions were plotted on a seven-point scale, meaning that by constructing a summation index we 
obtained a measurement between 0 and 12 with an asymmetry of 0.222 , approximately normal.

The measurement for Political Knowledge, for its part, was produced by combining three questions: 01. How long is the president's mandate in Brazil; 02 . How many states does Brazil have; 03. What is the name of the current US president? Since in the case of correct answers the value attributed to respondents is 01 , we used a summation procedure to construct a variable with a four-point scale too (0 to 03 ) with an inclination of -0.325 , that is, also approximately normal.

Hence we can formalize the following hypotheses:

\section{Openness to Experience}

H1a. Openness to Experience (Independent Variable) has an indirect positive effect on Involvement in Protests (Dependent Variable) by favouring the development of an Interest in Politics (Mediator).

H1b. Openness to Experience (IV) has an indirect positive effect on Involvement in Protests (DV) by favouring the development of Subjective Political Influence (M).

H1c. Openness to Experience (IV) has an indirect positive effect on Involvement in Protests (DV) by favouring the development of Political Knowledge $(\mathrm{M})$.

\section{Extraversion}

H2a. Extraversion (IV) has an indirect positive effect on Involvement in Protests (DV) by favouring the development of an Interest in Politics (M).

H2b. Extraversion (IV) has an indirect positive effect on Involvement in Protests (DV) by favouring the development of Subjective Political Influence (M).

H2c. Extraversion (IV) has an indirect positive effect on Involvement in Protests (DV) by favouring the development of the acquisition of Political Knowledge (M).

To test these hypotheses we need to make use of statistical models that combine techniques suitable for quantitative variables (such as the two mediating 
variables and the independent variable) and qualitative variables (our dependent binary variable). In sum, a procedure is needed that simultaneously utilizes linear and logistic regression and is capable of capturing direct and mediated effects.

Indirect effects have been calculated by researchers using a variety of approaches in recent years (KARLSON, HOLM and BREEN, 2012; KENNY, KASHY and BOLGER, 1998; MAcKINNON and DWYER, 1993), but all set out from some presuppositions and conditions that can only be assured when all the variables are continuous. When a combination of variables of this kind occurs with qualitative measurements (whether binary of multicategorical) the violation of the conditions renders the analysis inviable. Due to the growing need to combine variables measured at different levels, researchers have proposed solutions for reliable estimates (BARON and KENNY, 1986).

One of these involves the standardization of the coefficients before computing the indirect effects, thereby seeking to ensure conditions of comparability of the coefficients generated by the different models needed to analyse the direct and indirect effects. Without this procedure comparison is inviable since in regression based on ordinary least squares (OSL) the model's residual variance changes when variables are added or subtracted from the equation, while in the logistic models it remains fixed (BARON and KENNY, 1986). This difference leads to variation in the scale of the estimated coefficients, making any comparative analysis impossible.

The standardization proposed by Baron and Kenny (1986) uses standard deviations of the observed variables for the OSL-based models, and the standard deviation of a latent measure for the binary variable involved in the analysis in the case of the logistic models. Since the coefficients are standardized, the indirect effects are calculated as the product of the coefficients ${ }^{6}$.

The figures below illustrate the steps making up this model of analysis. In the first step (Figure 01) the existence of an effect of the IV on the DV is assessed, thereby configuring the 'path' 'c'. Figure 02 represents the next three steps: a. relative to the effect of the IV on the $\mathrm{M}$; b. relative to the effect of the $\mathrm{M}$ on the DV;

6 To test our hypotheses we adopted this approach with the use if the binary_mediation command in Stata. As this tool does not calculate standard errors or confidence intervals, we also used the bootstrap command. 
and finally c. which represents the mediated effect of the IV on the DV (KENNY, KASHY and BOLGER, 1998).

Figure 01. Direct effect

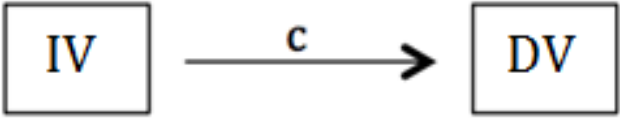

Note: IV = Independent Variable; DV = Dependent Variable.

Figure 02. Indirect effects

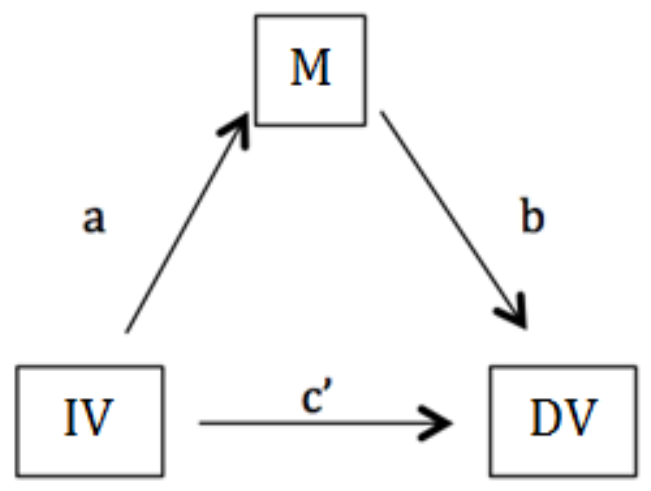

Note: IV = Independent Variable; DV = Dependent Variable; $\mathrm{M}=$ Mediator Variable.

Table 02 below shows fundamental descriptive statistics of the two IVs used and also the three Ms, including with their respective asymmetry tests. As for the mediating variables, it is interesting to observe the reduced means and also the high variability. In the next section we present the results of the conducted tests with the objective of testing our hypotheses.

Table 02. Descriptives of the IVs and Ms, Brazil, 2010

\begin{tabular}{lcccccc}
\hline & $\mathrm{N}$ & Minimum & Maximum & Mean & Deviation & Asymmetry \\
\hline Openness to Experience & 2446 & 0 & 12 & 09 & 2.77 & -0.681 \\
Extraversion & 2463 & 0 & 12 & 7.98 & 2.58 & -0.031 \\
Interest in Politics & 2452 & 0 & 3 & 0.97 & 0.91 & 0.723 \\
Political Influence & 2335 & 0 & 12 & 4.66 & 2.88 & 0.222 \\
Political Knowledge & 2394 & 0 & 3 & 1.77 & 0.945 & -0.325 \\
\hline
\end{tabular}

Source: LAPOP Brazil 2010. 


\section{Direct and mediated effects of 'openness to experience'}

Starting with Openness to Experience, the first step of the analysis requires confirmation of the direct effects of this predictor on the probability of involvement in political protest (DV), in what we call path 'c'. The results shown in Table 03 indicate the existence of a statistically significant effect of 0.109 and, calculating its exponential, it can be verified that each advance in the Openness scale increases the chance of participation by $11.5 \%$. It should be emphasized that this effect is not controlled by sociodemographic variables like sex, age and schooling, since the technique used to calculate the direct and indirect effects does not allow this inclusion. Such controls were employed by Ribeiro and Borba (2016) and the impact of Openness remained significant. Analysis of the path 'a' showed that Openness also significantly affects the measurement of interest in politics, at a fairly stringent level, despite the size of the positive effect being reduced (0.028).

Finally, in Table 03 we consider the effects of Openness and Interest on the same equation that takes as a dependent variable the qualitative measurement on involvement in protests. We can observe that the variable of personality continues to be a relevant predictor, but now with a slightly lower impact (9.5\%) on the probability of involvement. This suggests that some of its effect can take place indirectly, mediated by interest. Nonetheless, since the model presented in line 01 is logistical and the model in line 02 is based on ordinary least squares, the conclusion concerning the magnitude of the effects related to the mediation cannot be easily established by simple subtraction (BARON and KENNY, 1986), making it necessary to turn to the direct and indirect effects calculated through the standardization of coefficients, as we described in the methodology section. These indicators reveal that an indirect effect exists but is heavily reduced, its ratio to the direct effect being just 0.167. Considering the standardized mean of the total effects of 0.153 , the indirect effects attained just 0.022 . The hypothesis of mediation, though not refuted, loses much of its strength and leads us to conclude that the mechanism through which this personality trait affects this modality of political behaviour does not consistently provoke an increase in Interest. 
Table 03. Direct and mediated effects of 'openness to experience' and 'interest on protest', Brazil , 2010

\begin{tabular}{|c|c|c|c|}
\hline & & B & Sig. \\
\hline \multirow[t]{2}{*}{$\begin{array}{l}\text { Openness to Experience } \\
\text { on Protest }\end{array}$} & Openness to Experience & $\begin{array}{c}0.109 \\
(0.035)\end{array}$ & 0.002 \\
\hline & Constant & -3.791 & 0.000 \\
\hline \multirow[t]{2}{*}{$\begin{array}{l}\text { Openness to Experience } \\
\text { on Interest }\end{array}$} & Openness to Experience & $\begin{array}{c}0.028 \\
(0.006)\end{array}$ & 0.000 \\
\hline & Constant & 0.724 & 0.000 \\
\hline \multirow[t]{3}{*}{$\begin{array}{l}\text { Openness to Experience and } \\
\text { Interest on Protest }\end{array}$} & Openness to Experience & $\begin{array}{c}0.091 \\
(0.035)\end{array}$ & 0.010 \\
\hline & Interest & $\begin{array}{c}0.544 \\
(0.087)\end{array}$ & 0.000 \\
\hline & Constant & -4.264 & 0.000 \\
\hline \multicolumn{4}{|l|}{ Indirect Effect $=0.022(0.006)^{*}$} \\
\hline Direct Effect $=0.131(0.054)^{*}$ & \multicolumn{3}{|c|}{ Proportion of Mediated Effect $=0.143$} \\
\hline Total Effect $=0.153(0.055)^{*}$ & \multicolumn{3}{|c|}{ Indirect/Direct Effect Ratio $=0.167$} \\
\hline Path c effect $=0.164$ & \multicolumn{3}{|c|}{ Total/Direct Effect Ratio = 1.167} \\
\hline
\end{tabular}

Source: LAPOP Brazil Questionnaire 2010.

Note: * standard errors calculated using the Bootstrap method.

Turning to the second hypothesis, which tests the existence of effects of Openness mediated by Subjective Political Influence, it is essential to observe that the first step of the analysis needs to be repeated for all the hypotheses, since the number of cases included in the models alters when the mediating variables are substituted. As Table 04 indicates, despite this change the independent variable still proves to be a relevant predictor for involvement in protests, although its impact on the mediating variable does not attain the desirable level of significance. The model that controls the effects of Openness through Influence indicates that the latter affects the dependent variable in a significant and positive form. The calculation of the direct and indirect effects reveals that an almost insignificant proportion of the effect of the independent variable is due to mediation, thus leading to the rejection of our second hypothesis. 
Table 04. Direct and mediated effects of the 'openness to experience' and 'influence on protest', Brazil, 2010

\begin{tabular}{|c|c|c|c|}
\hline & & B & Sig. \\
\hline \multirow[t]{2}{*}{$\begin{array}{l}\text { Openness to Experience } \\
\text { on Protest }\end{array}$} & Openness to Experience & $\begin{array}{c}0.107 \\
(0.035)\end{array}$ & 0.002 \\
\hline & Constant & -3.772 & 0.000 \\
\hline \multirow[t]{2}{*}{$\begin{array}{l}\text { Openness to Experience } \\
\text { on Influence }\end{array}$} & Openness to Experience & $\begin{array}{c}0.004 \\
(0.022)\end{array}$ & 0.864 \\
\hline & Constant & 4.625 & 0.000 \\
\hline \multirow[t]{3}{*}{$\begin{array}{l}\text { Openness to Experience and } \\
\text { Influence on Protest }\end{array}$} & Openness to Experience & $\begin{array}{c}0.106 \\
(0.035)\end{array}$ & 0.003 \\
\hline & Influence & $\begin{array}{c}0.095 \\
(0.030)\end{array}$ & 0.001 \\
\hline & Constant & -4.193 & 0.000 \\
\hline \multicolumn{4}{|l|}{ Indirect Effect $=0.000(0.0001)^{*}$} \\
\hline Direct Effect $=0.157(-0.001)^{*}$ & \multicolumn{3}{|c|}{ Proportion of Mediated Effect $=0.003$} \\
\hline Total Effect $=0.157(-0.001)^{*}$ & \multicolumn{3}{|c|}{ Indirect/Direct Effect Ratio $=0.003$} \\
\hline Path c Effect $=0.159$ & \multicolumn{3}{|c|}{ Total/Direct Effect Ratio $=1.003$} \\
\hline
\end{tabular}

Source: LAPOP Brazil Questionnaire 2010.

Note: * standard errors calculated using the Bootstrap method.

Table 05. Direct and mediated effects of 'openness to experience' and 'knowledge on protest', Brazil, 2010

\begin{tabular}{|c|c|c|c|}
\hline & & $\mathrm{B}$ & Sig. \\
\hline \multirow[t]{2}{*}{$\begin{array}{l}\text { Openness to Experience } \\
\text { on Protest }\end{array}$} & Openness to Experience & $\begin{array}{c}0.103 \\
(0.034)\end{array}$ & 0.003 \\
\hline & Constant & -3.685 & 0.000 \\
\hline \multirow[t]{2}{*}{$\begin{array}{l}\text { Openness to Experience } \\
\text { on Knowledge }\end{array}$} & Openness to Experience & $\begin{array}{c}0.059 \\
(0.007)\end{array}$ & 0.000 \\
\hline & Constant & 1.243 & 0.000 \\
\hline \multirow[t]{3}{*}{$\begin{array}{l}\text { Openness to Experience and } \\
\text { Knowledge on Protest }\end{array}$} & Openness to Experience & $\begin{array}{c}0.079 \\
(0.035)\end{array}$ & 0.022 \\
\hline & Knowledge & $\begin{array}{c}0.460 \\
(0.104)\end{array}$ & 0.000 \\
\hline & Constant & -4.362 & 0.000 \\
\hline \multicolumn{4}{|l|}{ Indirect Effect $=0.040(-0.0001)^{*}$} \\
\hline Direct Effect $=0.117(-0.001)^{*}$ & \multicolumn{3}{|c|}{ Proportion of Mediated Effect $=0.255$} \\
\hline Total Effect $=0.157(0.002)^{*}$ & \multicolumn{3}{|c|}{ Indirect/Direct Effect Ratio = 0.343} \\
\hline Path c Effect $=0.156$ & \multicolumn{3}{|c|}{ Total/Direct Effect Ratio = 1.343} \\
\hline
\end{tabular}

Source: LAPOP Brazil Questionnaire 2010.

Note: * standard errors calculated using the Bootstrap method. 
The third and final hypothesis involving the psychological trait of Openness incorporates mediation through Political Knowledge and, following the same steps, we can observe that the effect of the independent variable remains significant, despite the impact having been subtly reduced, in comparison with the previous mediations (Table 05). Its effect on Political Knowledge also proved significant at a fairly stringent level, thus confirming the association found by previous studies (BEIER and ACKERMAN, 2001; HAMBRICK et al., 2008; WOLAK and MARCUS, 2007).

The model that present the controlled effects, for its part, confirms the hypothesis concerning the pronounced mediated effects, since it indicates that as well as Openness continuing to have a significant impact on the presence of Political Knowledge, the proportion of the mediated effect on the total is a little more than a quarter $(0.255)$ and more than a third of the direct effect, which we can consider relevant. Consequently we can conclude that this personality trait tends to affect protest behaviour mainly through a reinforcement of the cognitive dimension of the involvement in political affairs. Put otherwise, Openness to Experience seems to favour the acquisition of specific information on politics and this knowledge positively affects the chance of involvement in protest-based forms of political activism.

\section{Direct and mediated effects of 'extroversion'}

We can turn now to test the hypotheses relating to the effects of Extraversion, which we, Ribeiro and Borba (2016), found to be an important predictor for engagement in protests, even when considering important sociodemographic controls like age, sex and schooling. Following the same procedure described in the previous section, the first test includes Interest in Politics as mediating variable.

We can observe first of all that this trait positively affects $(0.082)$ the chance of involvement by $8.5 \%$ for each point in its scale, making it a relevant predictor of protest behaviour in the national setting (Table 06). Its effect on the average of Interest is a little smaller (3.3\%), but statistically significant at a fairly stringent level (0.000), indicating that individuals who more strongly show this trait tend to present greater interest in politics. However, the model combining the independent variable and the mediating variable indicates that the direct effect of Extraversion ceases to be significant when controlled by the mediating variable. The latter is a powerful predictor of involvement in

(2016) $10(3) \quad$ a


protests, increasing the probability of this behaviour by $74 \%$ for each additional point in its four-point scale. Calculating the proportions of the indirect effect on direct effect reveals that the former is equivalent to a third of the latter, but since the initial effect was already relatively small, the mediation led to its loss of statistical significance, above all due to the strong impact of Interest. Although a mediation can be identified in this case, the impact generated in the process of mediation is so small that the finding becomes insignificant in empirical terms.

Table 06. Direct and mediated effects of 'extraversion' and 'interest on protest, Brazil, 2010

\begin{tabular}{llcc}
\hline & & B & Sig. \\
\hline Extraversion on Protest & Extraversion & 0.082 & 0.016 \\
& Constant & $(0.034)$ & \\
& & -3.446 & 0.000 \\
Extraversion on Interest & Extraversion & 0.033 & 0.000 \\
& Constant & $(0.007)$ & \\
& & 0.724 & 0.000 \\
Extraversion and Interest on & Extraversion & 0.061 & 0.077 \\
Protest & & $(0.034)$ & \\
& Interest & 0.555 & 0.000 \\
& & $(0.087)$ & \\
& Constant & -3.938 & 0.000 \\
Indirect Effect $=0.025(0.000)^{*}$ & & & \\
Direct Effect $=0.083(0.000)^{*}$ & Proportion of Mediated Effect $=0.231$ & \\
Total Effect $=0.108(0.001)^{*}$ & Indirect/Direct Effect Ratio $=0.300$ & \\
Path c Effect $=0.116$ & Total/Direct Effect Ratio $=1.300$ & & \\
\hline
\end{tabular}

Source: LAPOP Brazil Questionnaire 2010.

Note: * standard errors calculated using the Bootstrap method.

Testing the mediation for Subjective Political Influence (Table 07), we initially observed that the measure for Extraversion continues to be a statistically significant predictor (0.046), albeit very close to the limit established for rejecting the hypothesis as null (0.05). Each additional point on the scale measuring this psychological trait increases the probability of involvement in protests by $07 \%$. However, the effect on the mediating variable was not shown to be relevant, remaining very far from the limit of significance (Table 7). We cannot, therefore, identify any mediated effects since this second step of the analysis does not confirm the existence of a relation between IV and M. This interpretation is corroborated by the information on direct and indirect effects, 
and their respective proportions, since the values are tiny (proportion of -0.015 of mediated effect on the total).

Table 07. Direct and mediated effects of 'extraversion' and influence on protest', Brazil, 2010

\begin{tabular}{|c|c|c|c|}
\hline & & $\mathrm{B}$ & Sig. \\
\hline \multirow[t]{2}{*}{ Extraversion on Protest } & Extraversion & $\begin{array}{c}0.068 \\
(0.034)\end{array}$ & 0.046 \\
\hline & Constant & -3.290 & 0.000 \\
\hline \multirow[t]{2}{*}{ Extraversion on Influence } & Extraversion & $\begin{array}{c}-0.011 \\
(0.023)\end{array}$ & 0.640 \\
\hline & Constant & 4.757 & 0.000 \\
\hline \multirow[t]{3}{*}{$\begin{array}{l}\text { Extraversion and Influence on } \\
\text { Protest }\end{array}$} & Extraversion & $\begin{array}{c}0.070 \\
(0.034)\end{array}$ & 0.040 \\
\hline & Influence & $\begin{array}{c}0.095 \\
(0.030)\end{array}$ & 0.001 \\
\hline & Constant & -3.788 & 0.000 \\
\hline \multicolumn{4}{|l|}{ Indirect Effect $=0.001(0.0001)^{*}$} \\
\hline Direct Effect $=0.098(-0.001)^{*}$ & \multicolumn{3}{|c|}{ Proportion of Mediated Effect $=-0.015$} \\
\hline Total Effect $=0.097(-0.001)^{*}$ & \multicolumn{3}{|c|}{ Indirect $/$ Direct Effect Ratio $=-0.015$} \\
\hline Path c Effect $=0.096$ & \multicolumn{3}{|c|}{ Total $/$ Direct Effect Ratio $=0.985$} \\
\hline
\end{tabular}

Source: LAPOP Brazil Questionnaire 2010.

Note: * standard errors calculated using the Bootstrap method.

In relation to the last hypothesis concerning the mediation of the measure of Political Knowledge, the effect of Extraversion remains significant for protest activism, increasing the chance of involvement by a little more than $08 \%$ (Table 08). This independent variable also proved to be a relevant predictor for the measure of Cognition, although its impact is reduced (just 0.05 in a scale that spans from 0 to 03 , presenting an mean of 1.77). The model controlling the direct effects with the mediating variable, for its part, indicates that the impact of Extraversion ceases to be significant (significance of 0.105) and that each rise in the measure of Knowledge increases the probability of involvement in protests by $60 \%$. This time the loss of significance of the independent variable does not lead to the rejection of the formulated hypothesis, since this occurred precisely because of the strong mediation, a conclusion corroborated by the ratio of 0.47 of the indirect effect on the direct effect and of 0.32 on the total effect. In this sense, the variable of Cognition again appears as a main mediating factor for this second observed personality trait. 
Table 08. Direct and mediated effects of 'extraversion' and 'knowledge on protest', Brazil, 2010

\begin{tabular}{llcc}
\hline & & \multicolumn{1}{c}{ B } & Sig. \\
\hline Extraversion on Protest & Extraversion & 0.078 & 0.021 \\
& Constant & $(0.034)$ & \\
& & -3.372 & 0.000 \\
Extraversion on Knowledge & Extraversion & 0.055 & 0.000 \\
& Constant & $(0.007)$ & 0.000 \\
Extraversion and Knowledge on & Extraversion & 1.133 & 0.005 \\
Protest & & 0.055 & 0.105 \\
& Knowledge & $0.034)$ & \\
& & 0.481 & 0.000 \\
& Constant & $-4.103)$ & 0.000 \\
Indirect Effect $=0.036(0.000)^{*}$ & & & \\
Direct Effect $=0.076(0.001)^{*}$ & Proportion of Mediated Effect $=0.320$ & \\
Total Effect $=0.112(0.001)^{*}$ & Indirect/Direct Effect Ratio $=0.471$ & \\
Path c Effect $=0.110$ & Total/Direct Effect Ratio $=1.471$ & & \\
\hline
\end{tabular}

Source: LAPOP Brazil Questionnaire 2010.

Note: * standard errors calculated using the Bootstrap method.

\section{Conclusions}

The recent advances in the area of the psychology of individual differences has enabled, over the last decade, other behavioural sciences to begin to explore the relations between the so-called personality traits and a wide range of attitudes and behaviours (MONDAK, 2010). In Political Science some studies have demonstrated a significant influence of this individual psychological constitution on the manifestation of values and attitudes and also on relevant political practices, including electoral turnout and non-electoral activism (BLAIS and LABBE ST-VINCENT, 2011; DENNY and DOYLE, 2008; GERBER et al., 2010; MONDAK, 2010; MONDAK et al., 2011). In the Brazilian context, we have already confirmed the relevance of these kinds of factors for a set of modalities of political engagement (RIBEIRO and BORBA, 2016).

These works, however, have been limited to identifying the conditioning relations and effects without exploring the underlying mechanisms of these relations or causalities. It is precisely this point that the present article has sought to address by testing a number of hypotheses concerning paths that may connect psychological 
characteristics to the manifestation of specific political attitudes and attributes, which, in turn, may condition protest-based political activism.

The set of tests refuted the hypotheses relating to the effects on protest of the mediating variables 'openness to experience' and 'extraversion', both on interest in politics and on the indicator of political influence. In other words, these personality traits do not make the individual more interested or leave him or her feeling more able to influence politics, attitudes considered central to explaining protest behaviour.

On the other hand, the study confirmed the existence of the mediation of personality traits linked to openness to experience and extraversion at a cognitive level, measured in our study as 'political knowledge'. What is suggested, in other words, is that citizens who possess these psychological traits seek out more information on the political universe, which allows them to take the decision to engage in a protest activity or movement. It seems therefore that the personality provides a kind of substrate for the development of cognitive skills relating to politics. As Gallego and Oberski (2012) assert, the evidence points to a relation that suggest a model of funnelled causality in which factors shaped in the past influence the manifestation of characteristics or attitudes developed more recently and the latter condition present-day behaviour. Due to their largely genetic bases (YAMAGATA et al., 2006), personality traits constitute a prior component, a base that conditions - in association with environmental and social factors - the development of characteristics and the acquisition of skills important for political activism. More specifically, in our models we identified that in the first stage of the mechanism the anterior factors affect the search for and acquisition of political knowledge, an important resource for civic engagement.

We cannot, of course, ignore the fact that the cognitive dimension is directly related to the objective conditions afforded by the individual's localization in the social structure. The main such condition is schooling, a variable already widely documented by the international literature on political participation (GALLEGO, 2015; RIBEIRO and BORBA, 2015; RIBEIRO and BORBA, 2016; VERBA, SCHLOZMAN and BRADY, 1995). Hence the open question is knowing how determined personality traits affect political cognition and whether this is an autonomous phenomenon or partially derived from the individual's localization in the social structure. The big challenge posed by this open dialogue between psychology, genetics and political science resides in clearly attributing

(2016) $10(3) \quad$ a $\quad$ a $0003-27 / 33$


the different weightings and magnitudes of the effects generated by each of these orders of factors and - even more challengingly - identifying the combinations of factors inherent to the constitution of the individual as a biological being and in his or her formation as a social being.

Working in this direction, the present study points to the possibilities for developing an interdisciplinary research agenda that attempts to discover the causal connections of the relation between personality (individual attribute), cognition (individual interaction $\mathrm{x}$ environment) and their impacts on the formation of attitudes, values and political behaviour itself.

Translated by David Rodgers Submitted on December 08, 2015 Accepted on August 08, 2016

\section{References}

ADORNO, Theodor; FRENKEL-BRUNSWIK, Else; LEVINSON, Daniel, and SANFORD, Nevitt (1950), The authoritarian personality. New York: Harper. 990pp.

ALLPORT, Gordon and ODBERT, Henry (1936), Trait-names: a psycho-lexical study. Psychological Review Company. Vol. 47, Edition 01. 171pp.

BARON, R. M., \& KENNY, D. A. (1986). The moderator-mediator variable distinction in social psychological research: Conceptual, strategic and statistical considerations. Journal of Personality and Social Psychology, Vol. 51, p.1173-1182.

BARRICK, Murray R. and MOUNT, Michael K. (1991), The big five personality dimensions and job performance: a meta-analysis. Personnel Psychology. Vol. 44, pp. 194-230.

BEIER, Margareth E. and ACKERMAN, Phillip L. (2001), Current events knowledge in adults: An investigation of age, intelligence and non-ability determinants. Psychology and Aging, 16, p. 615- 628.

BLAIS, Andre and LABBÉ-St-VINCENT, Simon (2011), Personality traits, political attitudes, and the propensity to vote. European Journal of Political Research. Vol. 50, № 03 , pp. 395-417.

BOLGER, Niall and SCHILLING, Elizabeth (1991), Personality and the problems of everyday life: the role of neuroticism in exposure and reactivity to daily stressors. Journal of Personality. Vol. 59, № 03, pp. 355-386.

BOOTH-KWLEY, Stephanie and VICKERS Jr., Ross R. (1994), Associations between major domains of personality and health behaviour. Journal of Personality. Vol. 62, № 03, pp. 281-298. 
BOHRNSTEDT, George; KNOKE, David (1989), Statistics for Social Data Analysis. Itasca, Ilinois: Peacock. 555pp.

BURKE, Ronald; MATTHIESEN, Stig Berge, and PALLESEN, Stale (2006), Workaholism, organizational life and well-being of Norwegian nursing staff. Career Development International. Vol. 11, № 05, pp. 463-477.

CATTELL, Raymond Bernard (1973), Personality and mood by questionnaire. San Francisco: Jossey-Bass. 532pp.

CATTELL, Raymond Bernard (1956), Validation and intensification of the sixteen personality factor questionnaire. Journal of Clinical Psychology. Vol. 12, № 03, pp. 205-214.

CATTELL, Raymond Bernard (1947), Confirmation and clarification of primary personality factors. Psychometrika. Vol. 12, № 03, pp. 197-220.

CONNOLLY, James J.; KAVANAGH, Erin J. and VISWESVARAN, Chockaligam (2007), The convergent validity between self and observer ratings of personality: a metaanalytic review. International Journal of Selection and Assessment. Vol. 15, № 01, pp. 110-117.

COSTA, Paul T. and McCRAE, Robert R. (2003), Personality in adulthood: a five-factor theory perspective. New York: Guilford. 268pp.

DALTON, Russell and ROHRSCHNEIDER, Robert (2002), Political action and the political context: A multi-level model of environmental activism. in: Citizen and Democracy in East and West: Studies in Political Culture and Political Process. Edited by FUCHS, D., ROLLER, E and WESSELS, B.. Wiesbaden: Westdeutscher Verlag, pp. 333-350.

DENNY, Kevin and DOYLE, Orla (2008), Political interest, cognitive ability and personality: determinants of voter turnout in Britain. British Journal of Political Science. Vol. 38, № 02, pp. 291-310.

DUDLEY, Nicole M.; ORVIS, Karin A.; LEBIECKI, Justin E., and CORTINA, José M. (2006), A meta-analytic investigation of conscientiousness in the prediction of job performance. Journal of Applied Psychology. Vol. 91, № 01, pp. 40-57.

ERIKSON, Erick (1969), Gandhi's truth: on the origins of militant nonviolence. New York: Norton. 474pp.

EYSENCK, Hans Jurgen (1954), The psychology of politics. New York: Routledge and Kegan Paul. 317pp.

EYSENCK, Hans Jurgen (1947), Dimensions of personality. London: Routledge. 308pp.

FRIEDMAN, Henry S.; TUCKER, Joan S.; TOMLINSON-KEASEY, Carol; SCHWARTZ, Joseph 
E.; WINGARD, Debora L., and CRIQUI, Michael H. (1993), Does childhood personality predict longevity? Journal of Personality and Social Psychology. Vol. 65, № 01, pp. 176-185.

GALLEGO, Aina (2015), Unequal political participation worldwide. Cambridge. Cambridge University Press. 252pp.

GALLEGO, Aina and OBERSKI, Daniel (2012), Personality and political participation: the mediation hypothesis. Political Behavior. Vol. 34, pp. 425-451.

GEORGE, Alexander L. and GEORGE, Juliette L. (1964), Woodrow Wilson and colonel house: a personality study. New York: Dover. 361pp.

GERBER, Alan S.; HUBER, Gregory A.; DOHERTY, David, and DOWLING, Conor M. (2011), The big five personality traits in the political arena. Annual Review of Political Science. Vol. 14, pp. 265-287.

GERBER, Alan S.; HUBER, Gregory A.; DOHERTY, David, and DOWLING, Conor M. (2010), Personality and political attitudes: relationships across issue domains and political contexts. American Political Science Review. Vol. 104, № 01, p. 111-133.

GOLDBERG, Lewis R. (1992), The development of markers for the big-five factor structure. Psychological Assessment. Vol. 04, № 01, pp. 26-42.

GREENSTEIN, Fred (2003), The George W. Bush presidency: an early assessment. Baltimore: Johns Hopkins University Press. 336pp.

HAMBRICK, David Z.; PINK, Jeffrey E.; MEINZ, Elizabeth J.; PETTIBONE, Jonathan C., and OSWALD, Frederick L. (2008), The roles of ability, personality, and interests in acquiring current events knowledge: A longitudinal study. Intelligence. Vol. 36, № 03, pp. 261-278.

HORN, Josh; NELSON, Carnot, and BRANNICK, Michael (2004), Integrity, conscientiousness and honesty. Psychological Reports. Vol. 95, pp. 27-38.

HUANG, Tsai-Jung; CHI, Su-Cheng., and LAWLER, John (2005), The relationship between expatriates. Personality traits and their adjustment to international assignments. International Journal of Human Resource Management. Vol. 16, pp. 1636-1670.

KARLSON, Kristian Bernt; HOLM, Anders and BREEN, Richard (2012), Comparing regression coefficients between same-sample nested models using logit and probit: A new method. Sociological Methodology, 42(1):286-313.

KENNY, David A.; KASHY, Deborah and BOLGER, Niall (1998), Data analysis in social psychology. In D. Gilbert, S. Fiske, and G. Lindzey (Eds.), Handbook of social psychology, 4th ed. New York: McGraw-Hill, pp. 233-265.

LAPOP, 2010.The Americas Barometer by the Latin American Public Opinion Project

(2016) $10(3) \quad$ a $\quad$ e0003-30/33


(LAPOP). Vanderbilt University.

LAURSEN, Brett.; PULKKINEN, Lea., and ADAMS, Ryan (2002), The antecedents and correlates of agreeableness in adulthood. Developmental Psychology. Vol. 38, № 04, pp. 591-603.

MACKINNON, David. P, WARSI, Ghulam, DWYER, James H. (1993), A Simulation Study of Mediated Effect Measures. Multivariate behavioral research. Vol. 30, No. 01, pp. 4162.

McCRAE, Robert and COSTA, Paul (2006), Cross-cultural perspectives on adult personality trait development. In: Handbook of personality development. Edited by MROCZEK, Daniel K. and LITTLE, Todd D. Hillsdale, New Jersey: Lawrence Erlbaum Associates, pp. 129-145.

McCRAE, Robert; COSTA, Paul (2003), Personality in Adulthood: a Five-Factor theory perspective. New York: The Guilford Press.

McCRAE, Robert; JANG, Kerry L.; LIVESLEY, W. John; RIEMANN, Rainer, and ANGLEITNER, Alois (2001), Sources of structure: genetic, environmental, and artifactual influences on the covariation of personality traits. Journal of Personality. Vol. 69, № 04, pp. 511-535.

McCRAE, Robert and COSTA, Paul (1989), Different points of view: self-reports and ratings in the assessment of personality. In: Recent advances in social psychology: an international perspective. Edited by FORGAS, Joseph P. and INNES, J. Michael. Amsterdam: Elsevier. pp. 429-439.

MISCHEL, Walter (1968), Personality and Assessment. New York: Wiley. 365pp.

MONDAK, Jeffery J. (2010), Personality and the foundations of political behaviour. Cambridge: Cambridge University Press. 246pp.

MONDAK, Jeffery J. and HALPERIN, Karen (2008), A framework for the study of personality and political behaviour. British Journal of Political Science. Vol. 38, № 02, pp. 335-362.

MONDAK, Jeffery J.; CANACHE, Damaris; SELIGSON, Mitchell, and HIBBING, Matthew V. (2011), The participatory personality: evidence from Latin America. British Journal of Political Science. Vol. 41, № 01, p. 211-221.

MONDAK, Jeffery J.; CANACHE, Damaris; SELIGSON, Mitchell; ANDERSON, Mary R., and HIBBING, Matthew V. (2010), Personality and civic engagement: an integrative framework for the study of trait effects on political behaviour. American Political Science Review. Vol. 104, № 01, p. 85-110.

MONDAK, Jeffery J.; CANACHE, Damaris; SELIGSON, Mitchell; ANDERSON, Mary R., and HIBBING, Matthew V. (2010), Personality and civic engagement: an integrative 
framework for the study of trait effects on political behavior. American Political Science Review. Vol. 104, № 01, p. 85-110.

MOSS, S. A.; McFARLAND, J.; NGU, S., and KIJOWSKA, A. (2007), Maintaining an open mind to closed individuals: the effects of resource availability and leadership style on the association between openness to experience and organizational commitment. Journal of Research in Personality. Vol. 41, № 02, pp. 259-275.

MUSSEN, Paul and WYSZYNSKI, Anne (1952), Personality and political participation. Human Relations. Vol. 05, № 01, p. 65-82.

NORRIS, Pippa (2007), Political activism: new challenges, new opportunities. In: The Oxford Handbook of Comparative Politics. Edited by BOIX, Carles and STOKES, Susan. Oxford: Oxford University Press, p. 628-652.

PULFORD, Briony and SOHAL, Harjit (2006), The influence of personality on students' confidence in their academic abilities. Personality and Individual Differences. Vol. 41, № 08, pp. 1409-1419.

RENSHON, Stanley (1995), The Clinton presidency: campaigning, governing and the psychology of leadership. Bolder: Westview. 261pp.

RIBEIRO, Ednaldo Aparecido and BORBA, Julian. (2016). Personalidade e protesto político na América Latina: bases psicossociais da contestação. Sociedade e Estado, Vol. 31, No. 2, pp. 373-402.

RIBEIRO, Ednaldo and BORBA, Julian (2015), Participação Política na América Latina. Maringá: Eduem, 156pp.

ROKEACH, Milton (1960), The open and closed mind: investigation into the nature of belief systems and personality systems. New York: Basic Books. 447pp.

SNIDERMAN, Paul (1975), Personality and democratic politics. Berkeley: University of California Press. 367pp.

STENNER, Karen (2005), The authoritarian dynamic. Cambridge: Cambridge University Press. 392pp.

SULLIVAN, John; PEIRESON, James; MARCUS, George (1982), Political tolerance and American democracy. Chicago: University Chicago Press.

TARROW, Sidney (1998), Power in movement: social movements and contentious politics. Cambridge: Cambridge University Press. 352pp.

TUPES, Ernest and CHRISTAL, Raymond (1961), Recurrent personality factors based on trait ratings. PubMed.gov. Vol. 60, № 02, pp. 225-251.

VECCHIONE, Michele and CAPRARA, Gian Vittorio (2009), Personality determinants of 
political participation: the contribution of traits and self-efficacy beliefs. Personality and Individual Differences. Vol. 46, № 04, p. 487-492.

VERBA, Sidney; SCHLOZMAN, Kay. L.; BRADY, Henry E. (1995), Voice and equality. Civic voluntarism in American politics. Boston: Harvard University Press, 662pp.

WINTER, David (2003), Measuring the motives of political actors at a distance. In: The psychological assessment of political leaders: with profiles of Saddam Hussein and Bill Clinton. Edited by POST, Jerrold. Ann Arbor: University of Michigan Press, pp. 153-177.

WOLAK, Jennifer; MARCUS, George (2007), Personality and emotional response: strategic and tactical responses to changing political circumstances. The Annals of the American Academy of Political and Social Science, n. 614, p. 172-195.

YAMAGATA, Shinji; SUZUKI, Atsunobu; ANDO, Juko; ONO, Yutaka; KIJIMA, Nobuhico; YOSHIMURA, Kimio; OSTENDORF, Fritz; ANGLEITNER, Alois; RIEMANN, Rainier; SPINATH, Frank M.; LIVESLEY, W. John, and JANG, Kerry L. (2006), Is the genetic structure of human personality universal? A cross-cultural twin study from North America, Europe, and Asia. Journal of Personality and Social Psychology. Vol. 90, № 06, p. 987-998. 